\title{
ASPIRE registry: Assessing the Spectrum of Pulmonary hypertension Identified at a REferral centre
}

\author{
J. Hurdman*, R. Condliffe*,\#, C.A. Elliot*,\#, C. Davies ${ }^{\star}$, C. Hill ${ }^{\star}$, J.M. Wild ${ }^{\#,+}$, \\ D. Capener ${ }^{+}$, P. Sephton*, N. Hamilton*, I.J. Armstrong*, C. Billings ${ }^{\S}$, A. Lawrie ${ }^{\#, f}$, \\ I. Sabroe ${ }^{\star, \#, * *}$, M. Akil ${ }^{\# \#, ~ L . ~ O ' T o o l e ~}{ }^{\text {Tथ }}$ and D.G. Kiely*,\#
}

ABSTRACT: Pulmonary hypertension (PH) is a heterogeneous condition. To date, no registry data exists reflecting the spectrum of disease across the five diagnostic groups encountered in a specialist referral centre.

Data was retrieved for consecutive, treatment-naïve cases diagnosed between 2001 and 2010 using a catheter-based approach. 1,344 patients were enrolled, with a mean follow-up of 2.9 yrs.

The 3-yr survival was $68 \%$ for pulmonary arterial hypertension (PAH), $73 \%$ for $\mathrm{PH}$ associated with left heart disease, $44 \%$ for $\mathrm{PH}$ associated with lung disease (PH-lung), $71 \%$ for chronic thromboembolic PH (CTEPH) and 59\% for miscellaneous PH. Compared with PAH, survival was inferior in PH-lung and superior in CTEPH $(p<0.05)$. Multivariate analysis demonstrated that diagnostic group independently predicted survival. Within PAH, Eisenmenger's survival was superior to idiopathic $\mathrm{PAH}$, which was superior to $\mathrm{PAH}$ associated with systemic sclerosis $(\mathrm{p}<0.005)$. Within PH-lung, 3-yr survival in sleep disorders/alveolar hypoventilation $(\mathbf{9 0 \%})$ was superior to $\mathrm{PH}$-lung with chronic obstructive pulmonary disease (41\%) and interstitial lung disease (16\%) $(p<0.05)$. In $\mathrm{CTEPH}$, long-term survival was best in patients with surgically accessible disease undergoing pulmonary endarterectomy.

In this large registry of consecutive, treatment-naïve patients identified at a specialist $\mathrm{PH}$ centre, outcomes and characteristics differed between and within PH groups. The current system of classification of PH has prognostic value even when adjusted for age and disease severity, emphasising the importance of systematic evaluation and precise classification.

KEYWORDS: Congenital heart disease, pulmonary hypertension, registry, survival, systemic sclerosis, thromboembolism

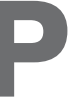

ulmonary hypertension $(\mathrm{PH})$ is defined as a mean pulmonary artery pressure $\left(\bar{P}_{\text {pa }}\right)$ of $\geqslant 25 \mathrm{mmHg}$ at right heart catheterisation (RHC) [1]. PH is a heterogeneous condition ranging from a rare, rapidly progressive vasculopathy (idiopathic pulmonary arterial hypertension (IPAH)) to more common and more minor elevations of pressure in the context of severe respiratory or cardiac disease. Greater understanding of underlying mechanisms resulted in the evolution of a classification system grouping diseases with shared pathophysiology with the intention of guiding treatment. The most recent classification identified five forms, as follows. Group 1: pulmonary arterial hypertension (PAH); group 2: $\mathrm{PH}$ associated with left heart disease (PH-LHD); group 3: $\mathrm{PH}$ associated with lung disease (PH-lung); group 4: chronic thromboembolic pulmonary hypertension (CTEPH); group 5: miscellaneous (PH-misc) [1].
The majority of studies in $\mathrm{PH}$ have focused on $\mathrm{PAH}$ and CTEPH but there are limited data comparing outcome in the subgroups of these major pre-capillary forms of $\mathrm{PH}$ in a contemporaneous cohort. PAH can occur without known cause (IPAH), or in association with congenital heart disease (PAH-CHD) or a number of systemic diseases, including connective tissue disease (PAH-CTD), particularly systemic sclerosis (PAH-SSc). In PAH, a pulmonary arteriopathy leads to progressively increasing pulmonary vascular resistance (PVR), resulting in right heart failure and early death. The emergence of targeted drug therapies for PAH since the late 1990s and pulmonary endarterectomy (PEA) as a definitive treatment for CTEPH revolutionised the previously limited options for patients [2-4]. Due to the rarity of these diseases, expense of therapies and required expertise, seven specialist
AFFILIATIONS

* Sheffield Pulmonary Vascular

Disease Unit,

'Dept of Radiology,

${ }^{\S}$ Respiratory Function Unit,

\#\# Dept of Rheumatology,

"Dept of Cardiology, Royal

Hallamshire Hospital,

${ }^{+}$Academic Unit of Radiology,

${ }^{f}$ Dept of Cardiovascular Science,

**Dept of Infection and Immunity

University of Sheffield, and

${ }^{*}$ National Institute for Health

Research Cardiovascular Biomedical

Research Unit, Sheffield, UK.

CORRESPONDENCE

D.G. Kiely

Sheffield Pulmonary Vascular

Disease Unit

Royal Hallamshire Hospital

Glossop Road

Sheffield

S10 2JF

UK

E-mail: david.kiely@sth.nhs.uk

Received:

May 092011

Accepted after revision:

Aug 142011

First published online:

Sept 012011 
PH centres that adhere to nationally agreed standards of care [5, 6] were first designated in the UK in 2001.

The Sheffield Pulmonary Vascular Disease Unit at the Royal Hallamshire Hospital (Sheffield, UK) is a large, adult UK PH centre serving a referral population of $\sim 15$ million [7]. We assess patients across the whole clinical spectrum of $\mathrm{PH}$ seen in the developed world. This has provided an opportunity to compare characteristics of extensively phenotyped, treatmentnaïve patients in the era of targeted drug therapies across the spectrum of $\mathrm{PH}$ identified at a specialist referral centre. Here we report the results of a large cohort study of all consecutive patients diagnosed with $\mathrm{PH}$ over a 9-yr period.

\section{METHODS}

All consecutive patients undergoing assessment of suspected PH between February 2001 and February 2010 were followed until November 1, 2010. All patients underwent a standard, systematic, diagnostic evaluation including echocardiography, detailed blood testing, exercise testing, lung function testing, overnight oximetry, isotope perfusion scanning, high-resolution computed tomography (HRCT), computed tomography pulmonary angiography and RHC. Cardiopulmonary magnetic resonance imaging (MRI) was routinely performed from 2004, while formal pulmonary angiography was performed when indicated. Diagnostic classification was by standard criteria following multidisciplinary assessment by experienced pulmonary vascular physicians and specialist radiologists.

In 2010, a detailed review of departmental databases and hospital records was performed. Data was captured in $>95 \%$ of cases for the vast majority of parameters. Only two variables had $<90 \%$ completeness (cardiac index in $87 \%$ and gas transfer (transfer factor of the lung for carbon monoxide $(T \mathrm{~L}, \mathrm{CO})$ ) in $88 \%$ ). Pulmonary function tests and World Health Organization (WHO) functional class obtained closest to the date of RHC were recorded as baseline measures. Exercise capacity was assessed using the distance achieved during the

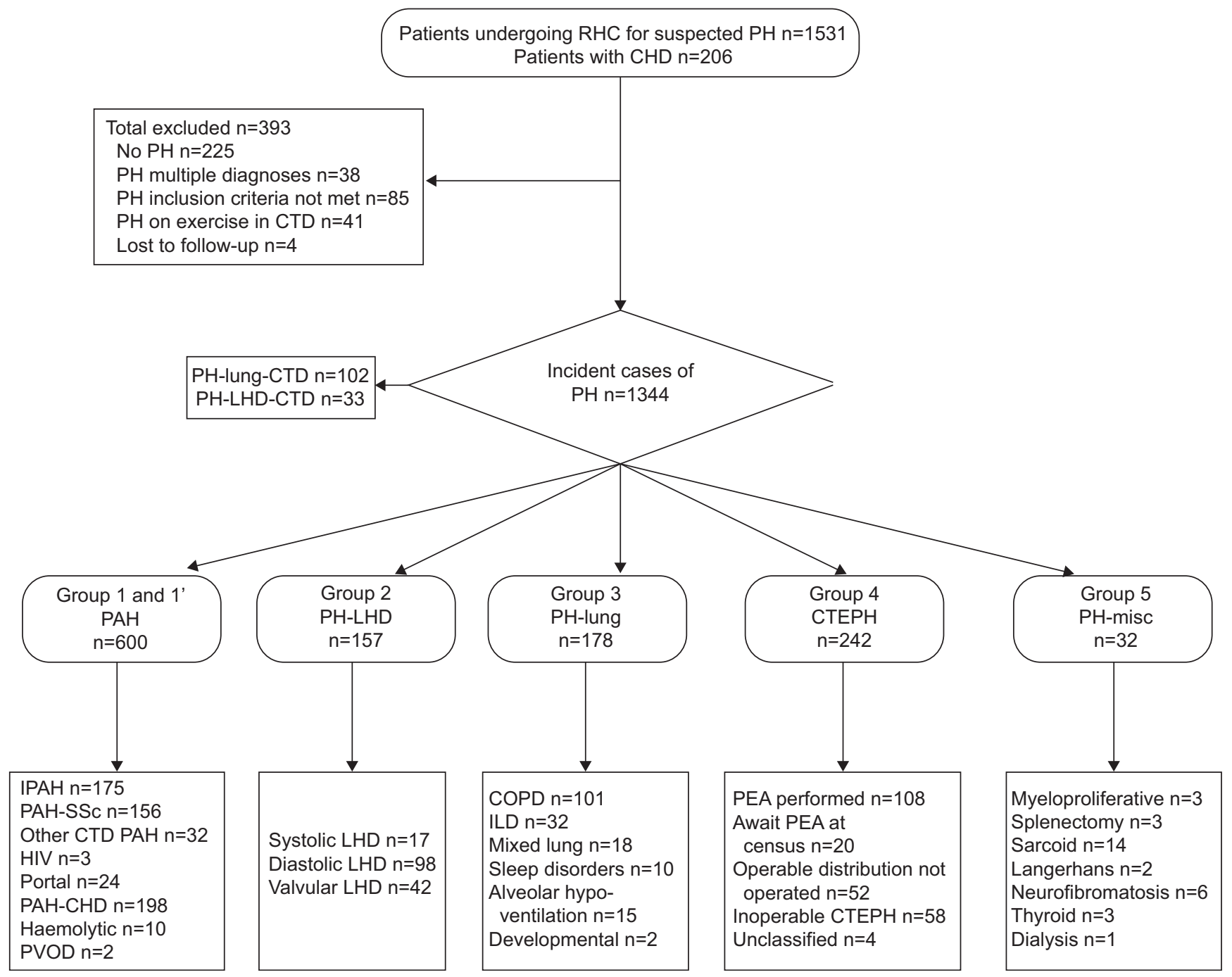

FIGURE 1. The study cohort. RHC: right heart catheterisation; PH: pulmonary hypertension; CHD: congenital heart disease; CTD: connective tissue disease; LHD: left heart disease; PAH: pulmonary arterial hypertension; PH-lung: $\mathrm{PH}$ associated with lung disease; $\mathrm{CTEPH}$ : chronic thromboembolic pulmonary hypertension; PH-misc: miscellaneous PH; IPAH: idiopathic PAH; SSc: systemic sclerosis; PVOD: pulmonary veno-occlusive disease; COPD: chronic obstructive pulmonary disease; ILD: interstitial lung disease; PEA: pulmonary endarterectomy. 
incremental shuttle walking test [8]. Patients were excluded if $\mathrm{PH}$ was attributable to multiple factors in unrelated diagnostic groups. The date of diagnosis was taken as the date of first RHC showing $\mathrm{PH}$, except in patients with Eisenmenger's syndrome in whom RHC is not routinely required [9], where the date of diagnosis was taken as the date first seen at our centre. A small number of patients $(n=5)$ commenced targeted therapy on specialist advice prior to urgent transfer to our centre. In these cases, the date of diagnosis was taken as the date therapy was started and their baseline haemodynamic data were not included in analyses.

Patients were excluded from group $1(\mathrm{PAH})$ if the pulmonary capillary wedge pressure $(P \mathrm{pcw})$ was $>15 \mathrm{mmHg}$. Patients with heritable PAH or PAH in association with anorexigen or amphetamine use were considered to have IPAH, as described elsewhere [10-12]. Patients with IPAH were excluded from the registry if the forced expiratory volume in $1 \mathrm{~s}$ and/or forced vital capacity (FVC) were consistently $<60 \%$ predicted. In the presence of significant parenchymal lung disease on HRCT, patients were diagnosed with $\mathrm{PH}$-lung as described previously, regardless of spirometry [13, 14]. PAH-CHD was subclassified in accordance with recent guidelines into four subgroups: Eisenmenger's syndrome, PAH associated with systemic-to-pulmonary shunts, PAH with small defects and PAH after corrective cardiac surgery [15]. Patients with PH-LHD were subclassified on the basis of echocardiographic and MRI assessment of left ventricular function, valvular sufficiency, left atrial size and presence of left ventricular hypertrophy as described elsewhere [16, 17]. Suitability for PEA in CTEPH was decided following assessment of clinical and radiological data at the UK national PEA centre. For subgroup analysis, patients who were awaiting PEA at census were excluded because many were treated medically prior to surgery and, thus, could not be clearly assigned to a treatment group.

PH-CTD may be present due to PAH, associated lung disease $[18,19]$ or left heart disease [20,21]. Patients with CTD and significant lung or left heart disease were therefore subclassified separately from groups 1, 2 and 3 to enable comparison of the full phenotypic range of PH-CTD. In PH-CTD, an FVC $<60 \%$ pred or the presence of moderate or severe fibrosis (more than one-third of the lung fields involved) on HRCT were used as criteria to define lung disease-associated $\mathrm{PH}(\mathrm{PH}-$ lung-CTD), as previously described [18, 19].

TABLE 1 Baseline characteristics for the five diagnostic groups

\begin{tabular}{|c|c|c|c|c|c|c|}
\hline & Overall & $\begin{array}{c}\text { Group } 1 \\
\text { PAH }\end{array}$ & $\begin{array}{l}\text { Group } 2 \\
\text { PH-LHD }\end{array}$ & $\begin{array}{l}\text { Group } 3 \\
\text { PH-lung }\end{array}$ & $\begin{array}{l}\text { Group } 4 \\
\text { CTEPH }\end{array}$ & $\begin{array}{l}\text { Group } 5 \\
\text { PH-misc }\end{array}$ \\
\hline Subjects n & 1344 & 598 & 157 & 178 & 242 & 32 \\
\hline Age yrs & $59 \pm 17$ & $54 \pm 18^{\bullet,+, \S}$ & $69 \pm 10^{\#, \S_{,} f}$ & $66 \pm 11^{\#, \S, f}$ & $61 \pm 15^{\# \cdot \cdot \cdot+}$ & $57 \pm 12^{\uparrow,+}$ \\
\hline Female & 62 & 70 & 69 & 38 & 54 & 59 \\
\hline WHO III/IV & $65 / 16$ & $64 / 14$ & $66 / 6$ & $62 / 27$ & 70/17 & $66 / 19$ \\
\hline ISWD m & $169 \pm 149$ & $189 \pm 156^{+}$ & $154 \pm 144$ & $111 \pm 104^{\#, \S}$ & $178 \pm 156^{+}$ & $140 \pm 114$ \\
\hline $\bar{P}$ ra $\mathrm{mmHg}$ & $11 \pm 6$ & $10 \pm 6^{\circ}$ & $15 \pm 6^{\#,+, \text { s,f }}$ & $10 \pm 6^{\circ}$ & $11 \pm 6^{\bullet}$ & $11 \pm 6^{\circ}$ \\
\hline $\bar{P}$ pa $\mathrm{mmHg}$ & $45 \pm 12$ & $48 \pm 13^{9,+}$ & $41 \pm 11^{\#, \S}$ & $41 \pm 11^{\#, \S}$ & $48 \pm 11^{\circ+}$ & $45 \pm 10$ \\
\hline $\mathrm{CI} \mathrm{L} \cdot \mathrm{min}^{-1} \cdot \mathrm{m}^{-2}$ & $2.7 \pm 0.9$ & $2.7 \pm 0.9^{\bullet}$ & $2.9 \pm 0.7^{\#, \S}$ & $2.8 \pm 0.9^{5}$ & $2.5 \pm 0.7^{\oplus,+, f}$ & $3.1 \pm 1.3^{\S}$ \\
\hline Ppcw mmHg & $13 \pm 7$ & $9 \pm 3^{\pi,+, 5}$ & $24 \pm 5^{\#,+, \xi_{, f}}$ & $13 \pm 6^{\#, 9, s}$ & $11 \pm 5^{\#, \cdot,+}$ & $11 \pm 5^{\circ}$ \\
\hline PVR dyn $\cdot \mathbf{s} \cdot \mathrm{cm}^{-5}$ & $654 \pm 430$ & $780 \pm 449^{\circ,+}$ & $289 \pm 225^{\#,+, \xi_{,}}$ & $539 \pm 376^{\#, \bullet, \S}$ & $735 \pm 389^{\circ++}$ & $656 \pm 431^{\circ}$ \\
\hline $\mathrm{Sv}, \mathrm{O}_{2} \%$ & $63 \pm 9$ & $63 \pm 9^{\S}$ & $64 \pm 8^{\S}$ & $65 \pm 8^{\S}$ & $60 \pm 9^{\#, \cdot,+}$ & $60 \pm 11$ \\
\hline FEV $1 \%$ pred & $73 \pm 22$ & $77 \pm 20^{\bullet+,, 5}$ & $67 \pm 20^{\#,+, \S}$ & $57 \pm 25^{\#, \cdot f f}$ & $78 \pm 19^{\circ}++$ & $69 \pm 24^{\circ++}$ \\
\hline FVC \% pred & $85 \pm 24$ & $88 \pm 22^{4++}$ & $76 \pm 22^{\#, \S}$ & $75 \pm 27^{\#, \varsigma}$ & $90 \pm 21^{\circ++}$ & $82 \pm 19$ \\
\hline$T L, C O \%$ pred & $54 \pm 22$ & $55 \pm 23^{\bullet,+\S}$ & $62 \pm 17^{+, f}$ & $35 \pm 18^{\# \cdot \bullet, \S}$ & $63 \pm 16^{\#,+, f}$ & $43 \pm 22^{\# \cdot, \cdot s}$ \\
\hline \multicolumn{7}{|l|}{ Maximal therapy } \\
\hline None & 28 & 11 & 87 & 51 & 14 & 28 \\
\hline $\mathrm{CCB}$ & 1 & 2 & 1 & 2 & 1 & 0 \\
\hline Oral monoRx & 46 & 49 & 12 & 39 & 65 & 31 \\
\hline Oral comb & 8 & 13 & 0 & 3 & 6 & 13 \\
\hline Prostanoid monoRx & 8 & 10 & 0 & 2 & 12 & 22 \\
\hline Prostanoid comb & 9 & 15 & 0 & 3 & 2 & 6 \\
\hline
\end{tabular}

Data are presented as mean \pm SD or \%, unless otherwise stated. PAH: pulmonary arterial hypertension; PH-LHD: pulmonary hypertension associated with left heart disease; PH-lung: pulmonary hypertension associated with lung disease; CTEPH: chronic thromboembolic pulmonary hypertension; PH-misc: miscellaneous pulmonary hypertension; WHO: World Health Organization functional class; ISWD: incremental shuttle walking distance; $\bar{P}_{\text {ra: }}$ mean right atrial pressure; $\bar{P}_{\text {pa: }}$ mean pulmonary artery pressure; $\mathrm{Cl}$ : cardiac index; Ppcw: pulmonary capillary wedge pressure; PVR: pulmonary vascular resistance; $\mathrm{Sv}, \mathrm{O}_{2}$ : mixed venous oxygen saturation; FEV1: forced expiratory volume in $1 \mathrm{~s}$; \% pred: \% predicted; FVC: forced vital capacity; $T \mathrm{~L}, \mathrm{CO}$ : transfer factor of the lung for carbon monoxide; CCB: calcium-channel blocker; oral monoRx: oral monotherapy; oral comb: combination phosphodiesterase-5 inhibitor and endothelin receptor antagonist; prostanoid monoRx: prostanoid monotherapy; prostanoid comb: prostanoid in combination with any other targeted therapy. ${ }^{*}: p<0.05$ in comparison to group $1 ;{ }^{\bullet}: p<0.05$ in comparison to group $2 ;{ }^{+}: p<0.05$ in comparison to group 3 ; $^{\text {s: }: ~} p<0.05$ in comparison to group 4 ; ${ }^{f}: p<0.05$ in comparison to group 5. 
Treatment was in accordance with contemporaneous guidelines and national commissioning policies $[6,22]$. Patients with a positive vasoreactivity test to nitric oxide, as defined by accepted practice at the date of RHC, were treated with calcium-channel blockers $[23,24]$. Endothelin receptor antagonists, phosphodiesterase- 5 inhibitors and prostanoids (nebulised or intravenous iloprost or subcutaneous treprostinil) were used as monotherapy or in combination, as clinically indicated. All patients were anticoagulated where indicated [25] and referred for transplant assessment as appropriate. The underlying medical conditions were diagnosed and managed by specialists in each field in accordance with contemporary medical practice.

The census point was date of death or lung transplantation, or November 1, 2010 in those with event-free survival. Mortality status was ascertained via the National Health Service enhanced reporting service death report. Patients who were untraceable at census $(n=4)$ were deemed lost to follow-up and were excluded. Ethical approval for analysis of routinely collected clinical data was granted by the North Sheffield Research Ethics Committee (Sheffield, UK).

\section{Statistical analysis}

Continuous variables were described by mean \pm SD. Multiple comparisons between groups were performed using ANOVA for parametric data. Categorical data were compared with the Chi-squared test. Event (death or transplantation)-free survival from date of diagnosis was estimated using the Kaplan-Meier method with comparison between groups performed by the log-rank test. Cox regression analysis was used to assess individual predictors of survival. A p-value of $<0.05$ was deemed

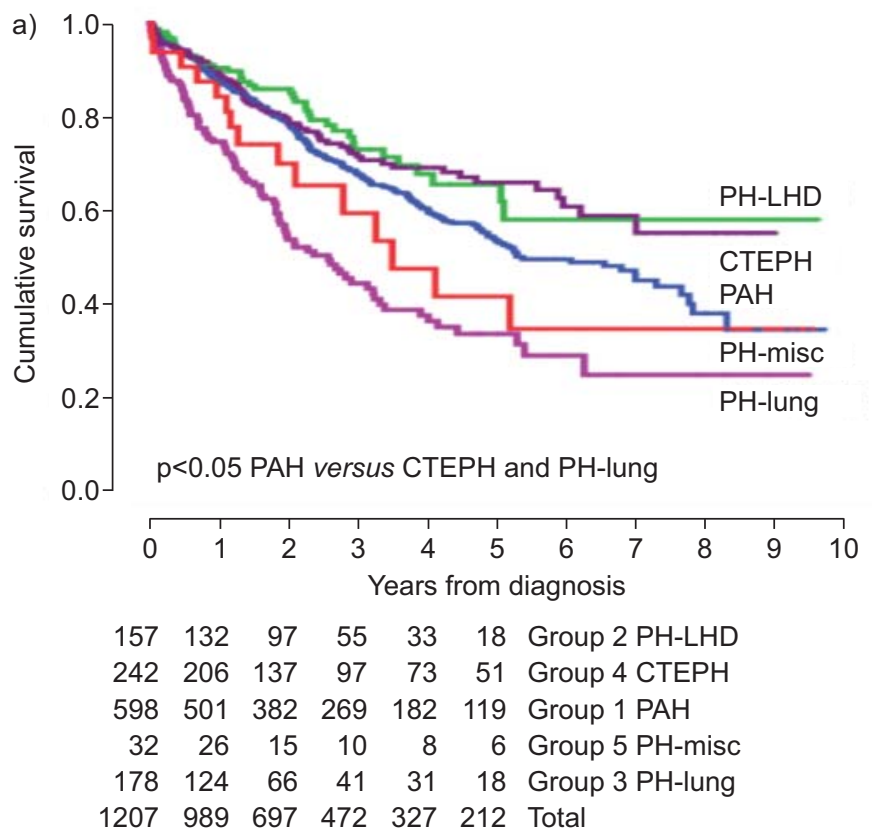

statistically significant throughout. Statistical analysis was performed using PASW Statistics v18 (SPSS, Chicago, IL, USA).

\section{RESULTS}

1,737 consecutive patients were evaluated for suspected $\mathrm{PH}$ using a RHC-based approach and 1,344 incident cases of $\mathrm{PH}$ were identified (fig. 1). 393 patients underwent RHC but did not meet inclusion criteria, including 225 with $\bar{P}_{\text {pa }}<25 \mathrm{mmHg}$, 41 with PH-CTD on exercise only $\left(\bar{P}_{\text {pa }} \geqslant 30 \mathrm{mmHg}\right.$ on exercise) who did not fulfil current diagnostic guidelines [1] and 38 patients with multiple factors contributing to $\mathrm{PH}$ where no principal cause could be distinguished. 85 patients did not meet the strict registry inclusion criteria and were excluded. For instance, 20 patients with a clear phenotype of $\mathrm{PAH}$ rather than PH-LHD had P pcw 16-18 mmHg and so were excluded.

Overall, the mean age at diagnosis was $59 \pm 17$ yrs with $44 \%$ aged $>65$ yrs and a female preponderance of $62 \%$. Ethnic origin was Caucasian in 92\%, African-Caribbean in 3\% and Asian in 5\%. During follow-up, 521 (39\%) patients died and eight $(1 \%)$ patients underwent lung transplantation. The number of incident cases increased throughout the study period from 25 in 2001 to 271 in 2009. Assuming a stable referral population of 15 million, between 2001 and 2009 the incidence of patients diagnosed at our centre with $\mathrm{PAH}$ increased from 0.9 to 6.1 , IPAH from 0.3 to 2.1, PAH-CTD from 0.3 to 2.4 and CTEPH from 0.3 to 3.7 cases per million per yr.

The maximal duration of follow-up was 9.7 yrs with a mean follow-up of $2.9 \pm 2.1$ yrs. Baseline characteristics, demographics and maximal therapy received for the five main groups are shown in table 1 . The 1- and 3-yr survival rates

b)

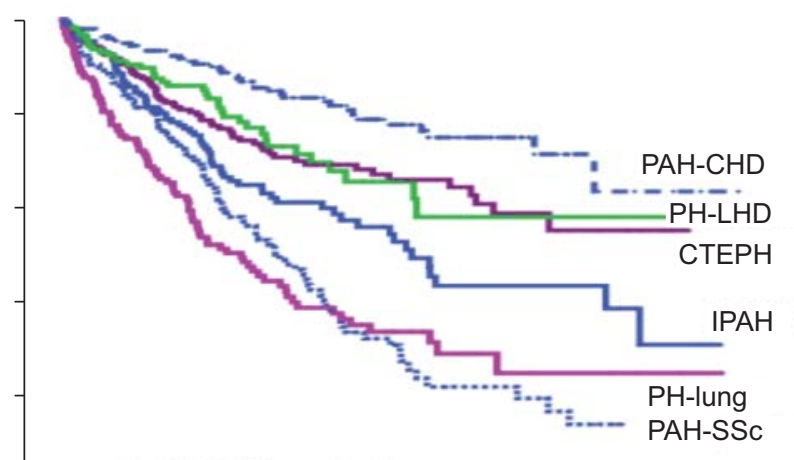

$p<0.05$ IPAH versus all other groups

\begin{tabular}{rrrrrrcrrrr}
\hline 0 & 1 & 2 & 3 & 4 & 5 & 6 & 7 & 8 & 9 & 10 \\
& \multicolumn{1}{c}{ Years from diagnosis } \\
198 & 179 & 156 & 122 & 90 & 64 & PAH-CHD & & \\
157 & 132 & 97 & 55 & 33 & 18 & PH-LHD & & \\
242 & 206 & 137 & 97 & 73 & 51 & CTEPH & & \\
175 & 143 & 102 & 67 & 44 & 30 & IPAH & & \\
178 & 124 & 66 & 41 & 31 & 18 & PH-lung & & \\
156 & 123 & 83 & 51 & 31 & 14 & PAH-SSc & & \\
1106 & 907 & 641 & 433 & 302 & 195 & Total & &
\end{tabular}

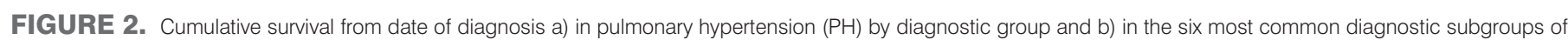

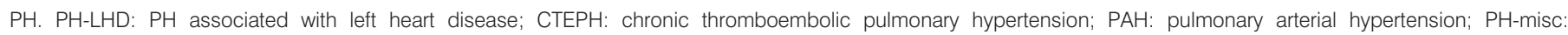

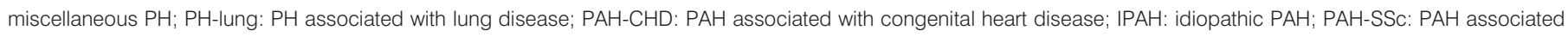
with systemic sclerosis. 
TABLE 2 Survival analysis to assess prognostic value of pulmonary hypertension group

Univariate HR p-value Multivariate HR p-value

\begin{tabular}{lcccc}
\hline Groups 1 and 2 & & & & \\
Age per yr & $1.03(1.03-1.04)$ & $<0.001$ & $1.03(1.02-1.05)$ & $<0.001$ \\
Cl per L·min ${ }^{-1} \cdot \mathrm{m}^{-2}$ & $0.71(0.59-0.84)$ & $<0.001$ & $0.72(0.60-0.86)$ & $<0.001$ \\
WHO I/II & Reference & & Reference & \\
WHO III/IV & $2.73(1.89-3.93)$ & $<0.001$ & $1.94(1.23-3.06)$ & $<0.005$ \\
Group 1 & Reference & & Reference & \\
Group 2 & $0.74(0.52-1.03)$ & 0.077 & $0.48(0.33-0.72)$ & $<0.001$ \\
Groups 1 and 3 & & & & \\
Age per yr & $1.04(1.03-1.05)$ & $<0.001$ & $1.03(1.02-1.04)$ & $<0.001$ \\
Cl per L·min ${ }^{-1} \cdot \mathrm{m}^{-2}$ & $0.67(0.58-0.78)$ & $<0.001$ & $0.66(0.54-0.78)$ & $<0.001$ \\
WHO I/II & Reference & & Reference & \\
WHO III/IV & $2.78(1.93-4.00)$ & $<0.001$ & $1.77(1.12-2.80)$ & $<0.05$ \\
Group 1 & Reference & & Reference & \\
Group 3 & $2.00(1.57-2.54)$ & $<0.001$ & $1.32(1.01-1.72)$ & $<0.05$ \\
Groups 1 and 4 & & & & \\
Age per yr & $1.03(1.03-1.04)$ & $<0.001$ & $1.03(1.02-1.04)$ & $<0.001$ \\
Cl per L·min ${ }^{-1} \cdot \mathrm{m}^{-2}$ & $0.71(0.60-0.84)$ & $<0.001$ & $0.66(0.55-0.79)$ & $<0.001$ \\
WHO I/II & Reference & & Reference & \\
WHO III/IV & $2.32(1.61-3.34)$ & $<0.001$ & $1.62(1.02-2.57)$ & $<0.05$ \\
Group 1 & Reference & & Reference & \\
Group 4 & $0.77(0.59-1.00)$ & $<0.05$ & $0.42(0.32-0.57)$ & $<0.001$ \\
\hline & & & & \\
\hline & & &
\end{tabular}

Data are presented as hazard ratio (HR) (95\% confidence interval). Cl: cardiac index; WHO: World Health Organization functional class. Group 1: pulmonary arterial hypertension; group 2: pulmonary hypertension associated with left heart disease; group 3: pulmonary hypertension associated with lung disease; group 4: chronic thromboembolic pulmonary hypertension. were $88 \%$ and $68 \%$ for group 1 (PAH), $90 \%$ and $73 \%$ for group 2 (PH-LHD), 65\% and 44\% for group 3 (PH-lung), $89 \%$ and $71 \%$ for group 4 (CTEPH) and $84 \%$ and $59 \%$ for group 5 (PHmisc) (fig. 2a). Compared with group 1, survival in group 3 was inferior and in group 4 was superior $(\mathrm{p}<0.05)$. To examine the prognostic value of $\mathrm{PH}$ group, data for patients in groups 2, 3 and 4 were in turn combined with data for patients in group 1. When age, WHO functional class and cardiac index were accounted for using multivariate Cox regression analysis, the $\mathrm{PH}$ diagnostic group independently predicted survival for each comparison (table 2). Comparative survival of the six most common forms of $\mathrm{PH}$ seen in clinical practice comprising $82 \%$ of cases is shown in figure $2 b$.

Therapeutic strategies changed over the study period as a result of an increase in available therapies and changing contemporaneous clinical guidelines and prescribing agreements. The intravenous prostanoid used during the registry period was iloprost, which, although not licensed for the treatment of $\mathrm{PH}$, is commonly used in the UK [26]. This was initially due to lower cost and its superior stability and half-life compared with epoprostenol. Selected patients outside groups 1 and 4 were treated with agreement of funding bodies. $13 \%$ of patients were included in previously published registries $[3,18]$.

\section{Group 1: PAH}

Baseline characteristics demonstrated differences between the subcategories within group 1 . Noticeably, patients with PAH-SSc had less severe haemodynamics but lower $T \mathrm{~L}, \mathrm{CO}$ than patients with IPAH, while those with PAH-CHD were younger (table 3). Within the combined IPAH group, six $(3 \%)$ patients had heritable $\mathrm{PAH}$, four $(2 \%)$ had a history of amphetamine or

TABLE 3 Baseline characteristics for group 1: pulmonary arterial hypertension

\begin{tabular}{|c|c|c|c|c|c|c|}
\hline & IPAH & SSc & CTD not SSc & Porto-pulmonary & All & Eisenmenger's \\
\hline Subjects $n$ & 175 & 156 & 32 & 24 & 198 & 108 \\
\hline Age yrs & $55 \pm 16^{\bullet, f}$ & $66 \pm 9^{\#,+, f}$ & $56 \pm 18^{\bullet, f}$ & $58 \pm 13^{f}$ & $42 \pm 17^{\#, \cdot,+, \S}$ & $37 \pm 15^{\#, \cdot,+, \text { s }}$ \\
\hline Female & $67^{\circ}$ & $87^{\#, \xi, f, \# \#}$ & $81^{\# \#}$ & $63^{\circ}$ & $62^{\circ}$ & $60^{\circ++}$ \\
\hline$\overline{\text { Pra }} \mathrm{mmHg}$ & $11 \pm 6^{\bullet++}$ & $9 \pm 5^{\#}$ & $7 \pm 6^{\#}$ & $10 \pm 7$ & & \\
\hline $\bar{P}$ pa $\mathrm{mmHg}$ & $53 \pm 13^{\bullet,+}$ & $43 \pm 13^{\#}$ & $45 \pm 11^{\#}$ & $49 \pm 11$ & & \\
\hline CI L. $\min ^{-1} \cdot \mathrm{m}^{-2}$ & $2.3 \pm 0.8^{\uparrow,+, \S}$ & $2.8 \pm 0.8^{\#}$ & $3.0 \pm 0.9^{\#}$ & $3.4 \pm 0.8^{\#}$ & & \\
\hline Ppcw mmHg & $10 \pm 3$ & $9 \pm 4$ & $9 \pm 3$ & $10 \pm 3$ & & \\
\hline PVR dyn $\cdot \mathbf{s} \cdot \mathrm{cm}^{-5}$ & $960 \pm 465^{\pi,+, 5}$ & $678 \pm 408^{\#}$ & $649 \pm 323^{\#}$ & $507 \pm 220^{\#}$ & & \\
\hline $\mathrm{Sv}, \mathrm{O}_{2} \%$ & $61 \pm 9^{\uparrow, \S}$ & $65 \pm 9^{\#}$ & $63 \pm 10$ & $69 \pm 9^{\#}$ & & \\
\hline
\end{tabular}

Data are presented as mean \pm SD or \%, unless otherwise stated. IPAH: idiopathic pulmonary arterial hypertension; SSc: systemic sclerosis; CTD: connective tissue disease; CHD: congenital heart disease; WHO: World Health Organization functional class; ISWD: incremental shuttle walking distance; $\bar{P}_{\text {ra: }}$ mean right atrial pressure; $\bar{P}$ pa: mean pulmonary artery pressure; $\mathrm{Cl}$ : cardiac index; Ppcw: pulmonary capillary wedge pressure; PVR: pulmonary vascular resistance; $\mathrm{Sv}, \mathrm{O}_{2}:$ mixed venous oxygen saturation; FEV1: forced expiratory volume in $1 \mathrm{~s} ; \%$ pred: \% predicted; FVC: forced vital capacity; $T L, C O$ : transfer factor of the lung for carbon monoxide. ${ }^{\#}: \mathrm{p}<0.05$ in comparison to IPAH; ": $p<0.05$ in comparison to SSc; ${ }^{+}: p<0.05$ in comparison to CTD not SSc; ${ }^{\text {s: }}: p<0.05$ in comparison to porto-pulmonary; ${ }^{\text {f: }} p<0.05$ in comparison to all $\mathrm{CHD} ;{ }^{\# \#:} \mathrm{p}<0.05$ in comparison to Eisenmenger's. 


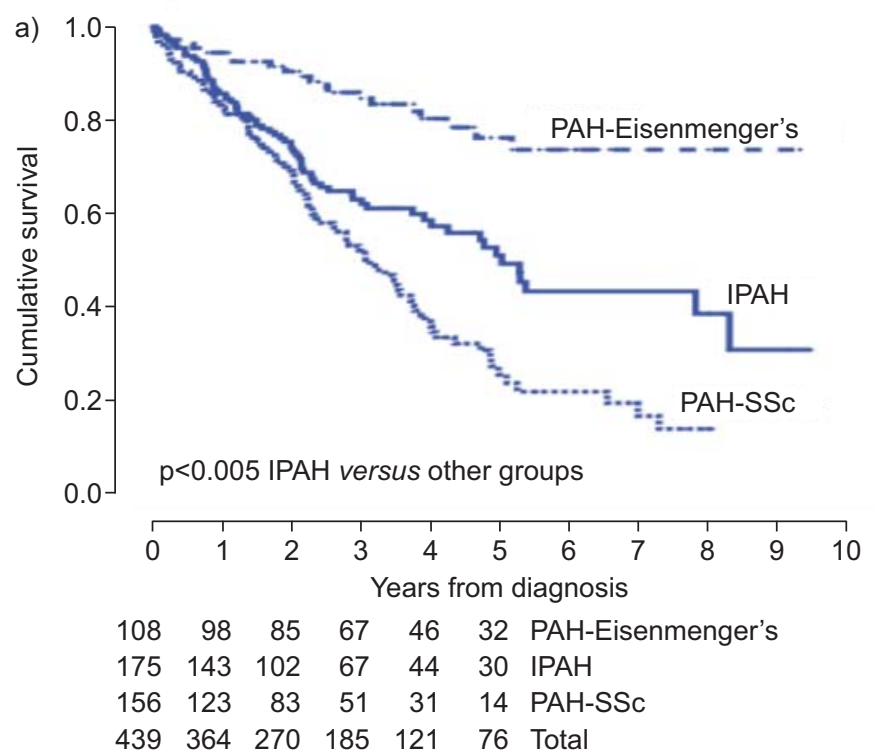

b)

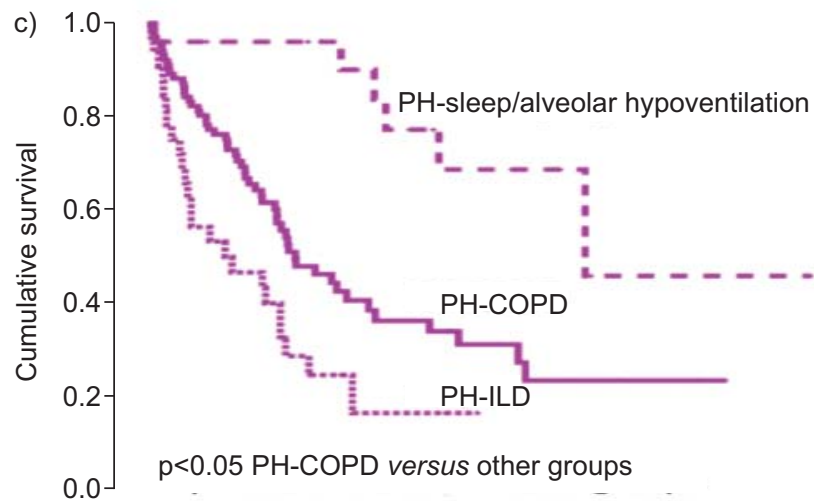

\begin{tabular}{rrrrrrrrrrr}
\hline 0 & 1 & 2 & 3 & 4 & 5 & 6 & 7 & 8 & 9 & 10 \\
& \multicolumn{8}{c}{ Years from diagnosis } \\
25 & 23 & 20 & 14 & 10 & 7 & PH-sleep/alveolar hypoventilation \\
101 & 72 & 33 & 20 & 16 & 9 & PH-COPD & & \\
32 & 17 & 7 & 2 & 2 & 0 & PH-ILD & & \\
158 & 112 & 60 & 36 & 28 & 16 & Total & &
\end{tabular}

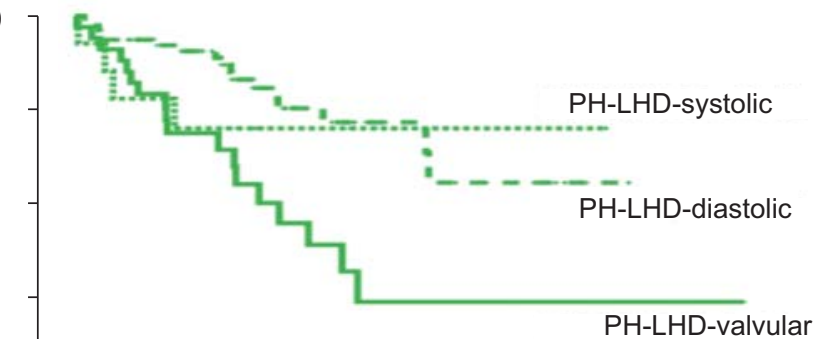

] $=0.001 \mathrm{PH}$-LHD-diastolic versus -valvular

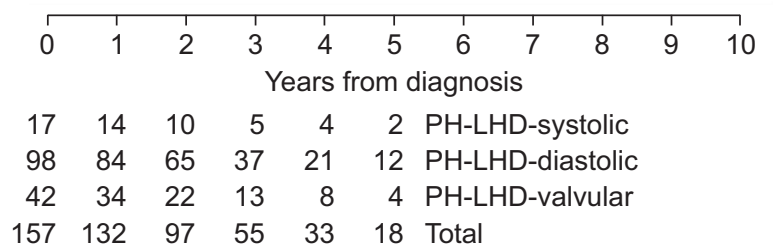

d)

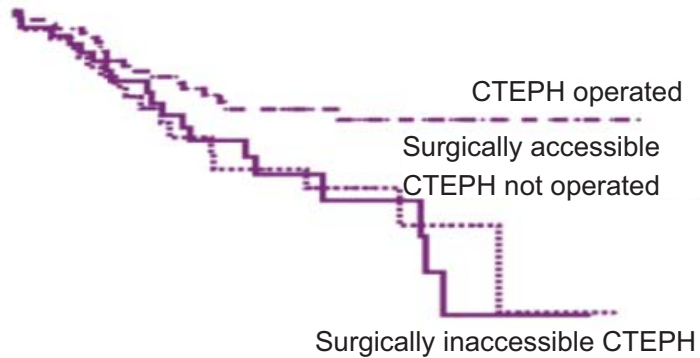

$\mathrm{p}<0.05$ CTEPH operated versus other groups

\begin{tabular}{|c|c|c|c|c|c|c|c|c|c|c|}
\hline 0 & 1 & 2 & 3 & 4 & 5 & 6 & 7 & 8 & 9 & 10 \\
\hline \multicolumn{11}{|c|}{ Years from diagnosis } \\
\hline 108 & 101 & 75 & 55 & 42 & 32 & \multicolumn{5}{|c|}{ CTEPH operated } \\
\hline 52 & 45 & 27 & 19 & 17 & 10 & \multicolumn{5}{|c|}{ CTEPH not operated } \\
\hline 58 & 51 & 34 & 23 & 14 & 9 & \multicolumn{5}{|c|}{ CTEPH surgically inaccessible } \\
\hline 218 & 197 & 136 & 97 & 73 & 51 & \multicolumn{5}{|c|}{ Total } \\
\hline
\end{tabular}

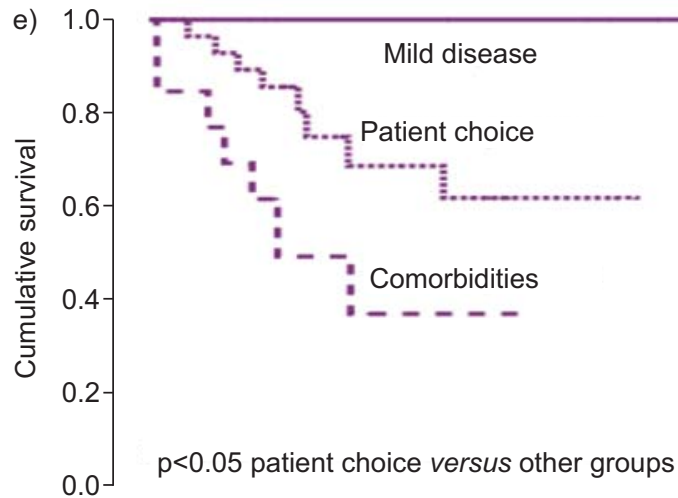

\begin{tabular}{lllllllllll}
\hline 0 & 1 & 2 & 3 & 4 & 5 & 6 & 7 & 8 & 9 & 10 \\
& & \multicolumn{1}{|l}{$\begin{array}{llll}1 \\
\text { Years from diagnosis }\end{array}$} & & &
\end{tabular}

$\begin{array}{lllllll}9 & 8 & 5 & 5 & 5 & 4 & \text { Mild haemodynamics }\end{array}$

$\begin{array}{lllllll}28 & 26 & 17 & 11 & 10 & 4 & \text { Patient choice }\end{array}$

$\begin{array}{lllllll}13 & 10 & 4 & 2 & 1 & 1 & \text { Comorbidities }\end{array}$

$\begin{array}{lllllll}50 & 44 & 26 & 18 & 16 & 9 & \text { Total }^{\#}\end{array}$ f)

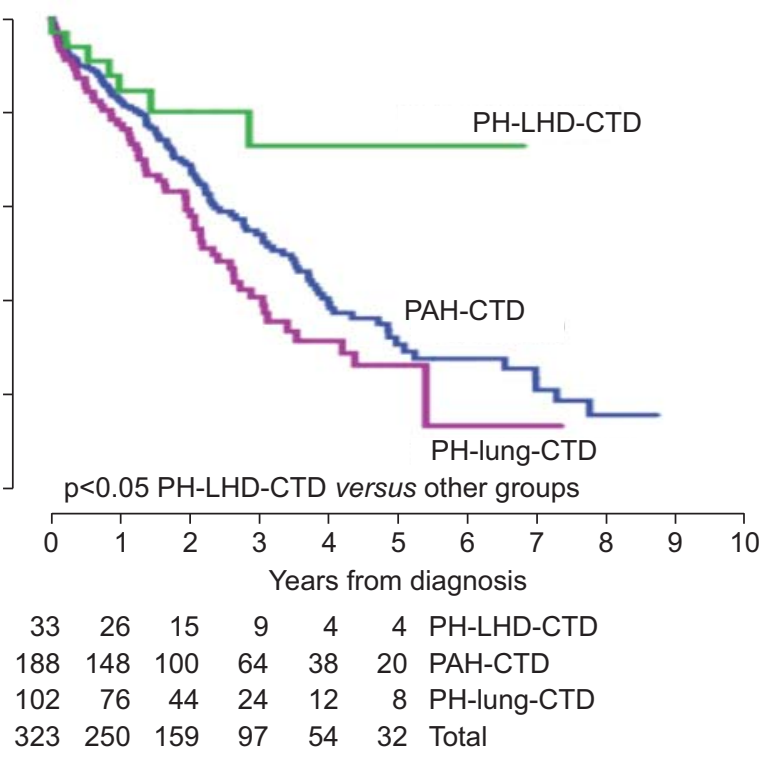


FIGURE 3. Cumulative survival from date of diagnosis: a) in group 1 pulmonary arterial hypertension (PAH) patients; b) in group 2 patients with pulmonary hypertension $(\mathrm{PH})$ associated with left heart disease (LHD); c) in group 3 patients with $\mathrm{PH}$ associated with lung disease; d) in group 4 chronic thromboembolic pulmonary hypertension (CTEPH) patients operated (undergoing pulmonary endarterectomy (PEA)), patients with surgically accessible CTEPH not operated and patients with surgically inaccessible disease; e) in patients with surgically accessible CTEPH not undergoing PEA by reason not operated; and f) in patients with PH associated with connective tissue disease (CTD) by type of PH. IPAH: idiopathic PAH; SSc: systemic sclerosis; COPD: chronic obstructive pulmonary disease; ILD: interstitial lung disease. ${ }^{\#}$ : two patients were excluded because it was unclear whether PEA was not undertaken primarily due to comorbidities or patient choice.

anorexigen exposure, while $6 \%$ had a positive vasodilator response to nitric oxide during RHC. The 3-yr survival in IPAH was $63 \%$, poorer than in PAH-CHD (85\%) but significantly better than PAH-SSc $(52 \% ; \mathrm{p}<0.01)$ (fig. 3a).

\section{Group 2: PH-LHD}

There was no significant difference in outcome between patients with diastolic or systolic left ventricular dysfunction, although the numbers in the latter group were small. Survival in $\mathrm{PH}$ secondary to valvular heart disease (PH-LHD-valvular), comprising 22 mitral, four aortic and 16 mixed mitral/aortic significant valvular abnormalities, was significantly worse than in $\mathrm{PH}$ secondary to diastolic dysfunction (PH-LHDdiastolic; $p=0.001$ ) (fig. $3 b$ ). $36 \%$ of patients with PH-LHDvalvular had undergone valve replacement. Patients with PH-LHD had relatively well-maintained cardiac output and milder elevation of PVR but had higher right atrial pressures compared with IPAH (table 4).

\section{Group 3: PH-lung}

Survival in patients with PH-lung was dependent on subgroup. The 3-yr survival in $\mathrm{PH}$ associated with sleepdisordered breathing/alveolar hypoventilation (90\%) was markedly better than $\mathrm{PH}$ associated with chronic obstructive pulmonary disease (PH-COPD; 41\%; $\mathrm{p}=0.001$ ), which in turn was better than $\mathrm{PH}$ associated with interstitial lung disease
$(16 \% ; p=0.011)$ (fig. 3c). In PH-COPD, a moderate elevation in PVR but significant reduction in TL,CO was observed (table 5).

\section{Group 4: CTEPH}

242 patients were diagnosed with CTEPH. In four cases, confident delineation of disease distribution was impossible due to suboptimal imaging that could not be repeated. At the census date, 20 patients had not undergone planned PEA and were excluded from further analysis. Survival of the remaining 218 patients is illustrated in figure $3 \mathrm{~d}$. The 3-yr survival in patients undergoing PEA was $83 \%$, significantly superior to surgically inaccessible CTEPH or unoperated surgically accessible CTEPH $(\mathrm{p}<0.05)$. There was no significant difference in haemodynamic severity between these groups (table 6). Survival in surgically inaccessible CTEPH did not differ significantly from IPAH (not shown on figure). The 3-yr survival in patients who were not candidates for PEA due to the presence of significant comorbidities $(37 \%)$ was inferior to that in patients who declined PEA (69\%), which was inferior to those with disease considered too mild to require intervention $(100 \%$; $\mathrm{p}<0.05)$ (fig. 3e). $89(82 \%)$ of 108 patients who underwent PEA received bridging pulmonary vascular therapy (69 oral monotherapy and 20 prostanoid-based therapy).

\section{Group 5: PH-misc}

32 patients were diagnosed with $\mathrm{PH}$ in the subcategories of group 5. PH associated with sarcoidosis was most common

TABLE 4 Baseline characteristics for group 2: pulmonary hypertension due to left heart disease

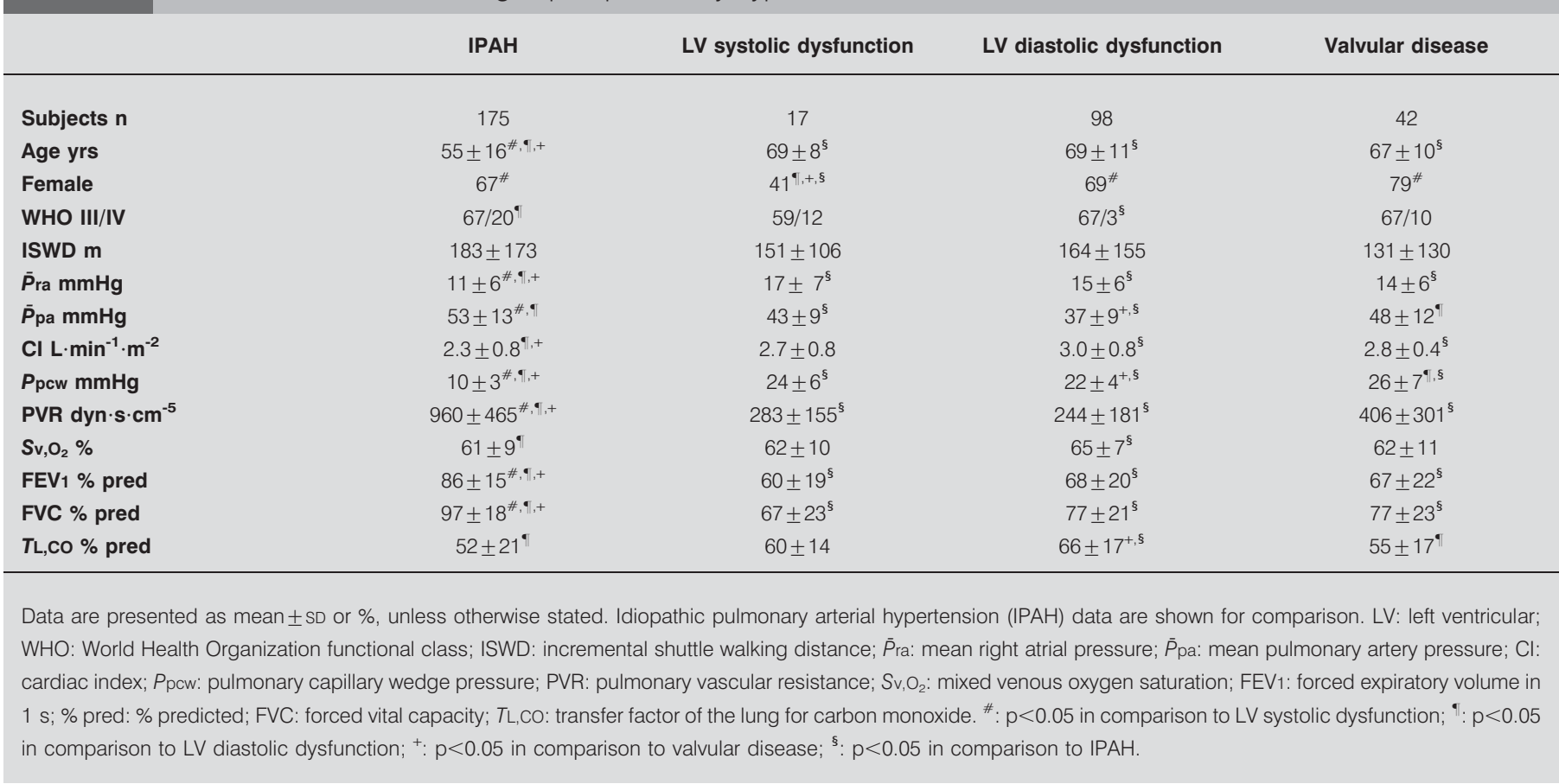


TABLE 5 Baseline characteristics for group 3: pulmonary hypertension due to lung disease and/or hypoxia

\begin{tabular}{|c|c|c|c|c|}
\hline & IPAH & COPD & ILD & $\begin{array}{c}\text { Sleep disorders and alveolar } \\
\text { hypoventilation }\end{array}$ \\
\hline Subjects n & 175 & 101 & 32 & 25 \\
\hline Age yrs & $55 \pm 16^{\# \cdot \bullet}$ & $69 \pm 10^{5}$ & $68 \pm 11^{\S}$ & $61 \pm 10$ \\
\hline Female & $67^{\# \cdot 9,+}$ & $37^{\S}$ & $22^{\S}$ & $44^{\S}$ \\
\hline WHO III/IV & $67 / 20^{\circ}$ & $67 / 25^{+}$ & $53 / 44^{+, 5}$ & $67 / 8^{\#, 9}$ \\
\hline ISWD m & $183 \pm 173^{\#, 9}$ & $102 \pm 105^{\S}$ & $97 \pm 97^{\S}$ & $145 \pm 99$ \\
\hline $\bar{P}$ ra $\mathrm{mmHg}$ & $11 \pm 6$ & $10 \pm 5$ & $8 \pm 7$ & $11 \pm 7$ \\
\hline $\bar{P}_{\text {pa }} \mathbf{m m H g}$ & $53 \pm 13^{\# \cdot \cdot++}$ & $43 \pm 11^{\S}$ & $39 \pm 9^{\S}$ & $37 \pm 10^{\S}$ \\
\hline $\mathrm{CI} \mathrm{L} \cdot \mathrm{min}^{-1} \cdot \mathrm{m}^{-2}$ & $2.3 \pm 0.8^{\#,+}$ & $2.8 \pm 0.9^{5}$ & $2.5 \pm 0.6^{+}$ & $3.2 \pm 0.7^{\bullet, 5}$ \\
\hline Ppcw mmHg & $10 \pm 3^{\#,+}$ & $13 \pm 5^{+, \S}$ & $11 \pm 8^{+}$ & $16 \pm 10^{\# \cdot \bullet \cdot s}$ \\
\hline PVR dyn $\cdot \mathbf{s} \cdot \mathrm{cm}^{-5}$ & $960 \pm 465^{\#, \uparrow,+}$ & $568 \pm 382^{\S}$ & $560 \pm 321^{\S}$ & $375 \pm 284^{\S}$ \\
\hline $\mathrm{S}_{\mathrm{v}, \mathrm{O}_{2}} \%$ & $61 \pm 9^{\#,+}$ & $64 \pm 8^{\S}$ & $63 \pm 10$ & $69 \pm 8^{\S}$ \\
\hline FEV 1 \% pred & $86 \pm 15^{\#, \cdot,++}$ & $59 \pm 26^{\S}$ & $66 \pm 25^{\S}$ & $51 \pm 23^{\S}$ \\
\hline FVC \% pred & $97 \pm 18^{\# \cdot 9 \cdot+}$ & $85 \pm 25^{\bullet,+,}$ & $66 \pm 25^{\#, \S}$ & $56 \pm 23^{\#, \S}$ \\
\hline$T L, C O \%$ pred & $52 \pm 21^{\# \cdot 9}$ & $32 \pm 16^{+, \S}$ & $32 \pm 9^{+, \S}$ & $57 \pm 19^{\# \cdot \bullet}$ \\
\hline
\end{tabular}

Data are presented as mean \pm SD or \%, unless otherwise stated. Idiopathic pulmonary arterial hypertension (IPAH) data are shown for comparison. COPD: chronic obstructive pulmonary disease; ILD: interstitial lung disease; WHO: World Health Organization functional class; ISWD: incremental shuttle walking distance; $\bar{P}_{\mathrm{ra}}$ : mean right atrial pressure; $\bar{P}_{\text {pa: }}$ mean pulmonary artery pressure; $\mathrm{Cl}$ : cardiac index; Ppcw: pulmonary capillary wedge pressure; PVR: pulmonary vascular resistance; $S_{v}, \mathrm{O}_{2}:$ mixed venous oxygen saturation; FEV1: forced expiratory volume in $1 \mathrm{~s}$; \% pred: \% predicted; FVC: forced vital capacity; $T$ L, Co: transfer factor of the lung for carbon monoxide. ${ }^{\#}$ : $p<0.05$ in comparison to COPD; ${ }^{\bullet}: \mathrm{p}<0.05$ in comparison to ILD; ${ }^{+}: \mathrm{p}<0.05$ in comparison to sleep/alveolar hypoventilation; ${ }^{\text {s. }} \mathrm{p}<0.05$ in comparison to IPAH.

$(n=14)$ with a 3-yr survival of $63 \%$. Detailed interpretation of survival and baseline data for patients in group 5 was not performed due to limited numbers.

\section{PH-CTD}

In total, 323 patients with PH-CTD met inclusion criteria: 188 with isolated PAH, 102 with PH-lung-CTD and 33 with PH-CTD associated with LHD (PH-LHD-CTD). In isolated PAH-CTD, SSc was the most frequent underlying CTD, present in $156(83 \%)$ patients. SSc was of the limited cutaneous form in $94 \%$ of these cases and there was no significant difference in survival between PAH associated with diffuse or limited SSc. 32 patients without SSc were diagnosed with isolated PAH-CTD including nine patients with undifferentiated CTD, seven with systemic

TABLE 6 Baseline characteristics for group 4: chronic thromboembolic pulmonary hypertension (CTEPH)

\begin{tabular}{|c|c|c|c|c|}
\hline & IPAH & CTEPH operated & CTEPH not operated & CTEPH surgically inaccessible \\
\hline Subjects $n$ & 175 & 108 & 52 & 58 \\
\hline Female & $67^{\#}$ & $44^{\pi+,+\S}$ & $67^{\#}$ & $60^{\#}$ \\
\hline WHO III/IV & $67 / 20$ & $72 / 14$ & $65 / 24$ & $74 / 14$ \\
\hline ISWD m & $183 \pm 173$ & $203 \pm 174$ & $129 \pm 122$ & $177 \pm 141$ \\
\hline $\mathrm{CI} \mathrm{L} \cdot \mathrm{min}^{-1} \cdot \mathrm{m}^{-2}$ & $2.3 \pm 0.8$ & $2.3 \pm 0.6$ & $2.5 \pm 0.9$ & $2.6 \pm 0.8$ \\
\hline Ppcw mmHg & $10 \pm 3^{+}$ & $10 \pm 4$ & $10 \pm 5$ & $11 \pm 6^{\S}$ \\
\hline PVR dyn $\cdot \mathbf{s} \cdot \mathrm{cm}^{-5}$ & $960 \pm 465^{\#, 9,+}$ & $780 \pm 389^{\S}$ & $740 \pm 373^{\S}$ & $689 \pm 424^{\S}$ \\
\hline $\mathrm{Sv}, \mathrm{O}_{2} \%$ & $61 \pm 9$ & $60 \pm 8$ & $60 \pm 9$ & $61 \pm 10$ \\
\hline FEV $1 \%$ pred & $86 \pm 15^{\#, 9,+}$ & $80 \pm 16^{\S}$ & $74 \pm 23^{\S}$ & $79 \pm 21^{\S}$ \\
\hline FVC \% pred & $97 \pm 18$ & $92 \pm 17$ & $89 \pm 25$ & $89 \pm 23$ \\
\hline
\end{tabular}


lupus erythematosus, six with overlap CTD, five with mixed CTD, three with rheumatoid arthritis and two patients with Sjögren's syndrome. In patients with CTD other than SSc, the majority of $\mathrm{PH}$ was associated with parenchymal lung disease. The 3-yr survival in PH-LHD-CTD (73\%) was significantly better than in PAH-CTD (54\%) and PH-lung-CTD (40\%; $\mathrm{p}<0.05)$ (fig. 3f).

\section{DISCUSSION}

This study reports the findings of a large cohort of consecutive cases of $\mathrm{PH}$ identified at a specialist centre. All patients were treatment-naïve at entry and diagnosis was made at RHC (with the exception of selected patients with CHD). Importantly, this study provides detailed phenotypic and prognostic information on consecutive, incident cases in the major subgroups of PAH and CTEPH and highly selected, consecutive patients with PH-LHD and PH-lung referred for assessment of suspected severe $\mathrm{PH}$. Our results demonstrate the differences between these distinct groups of patients with $\mathrm{PH}$ attending a specialist $\mathrm{PH}$ centre and highlight the need for precise characterisation.

There are several clinically important findings from our cohort regarding the previously well-described diagnostic groups 1 and 4 . As expected, there was a marked difference in survival between the three most common forms of group 1 (Eisenmenger's, IPAH and PAH-CTD), probably related to differences in demographic characteristics such as age, in the ability of the right ventricle to cope with increased afterload and in the severity of the underlying pulmonary vasculopathy $[27,28]$. In the CTEPH group, patients with operable disease who underwent PEA had the best long-term outcome, confirming the importance of appropriate operative intervention. We have also shown that CTEPH patients with operable disease considered too mild to warrant PEA had an excellent survival rate. Patients with surgically accessible disease who did not proceed to PEA because of comorbidities had poorer survival than those with operable disease who chose to be treated medically. Overall, patients with unoperated surgically accessible CTEPH had similar outcomes to patients with disease of a surgically inaccessible distribution. This emphasises the importance of effective identification and counselling of patients with potentially operable CTEPH. In patients with a high pre-test probability of $\mathrm{PAH}$, such as those with CTD, we have demonstrated the importance of identifying the type of $\mathrm{PH}$ as it influences prognosis. In CTD, those with PH-LHDCTD have a significantly improved survival compared with PAH-CTD and PH-lung-CTD.

Many additional findings regarding PAH and CTEPH concur with those previously described [3, 18, 29-33]. The proportion of patients with IPAH with a positive vasodilator response $(6 \%)$ was of a similar order to that in previous registries [29, 30]. As observed elsewhere, survival in PAH-SSc was inferior to that of IPAH $[18,34,35]$ and the number of cases of PAHCTD associated with CTDs other than SSc was small [18, 3641]. In contrast to the French registry, limited cutaneous SSc was far more common than the diffuse form $(94 \%$ versus $67 \%$ of PAH-CTD-SSc) [29]. The proportion of patients with PH-CTD with LHD was also lower. These differences may reflect varying approaches to screening, referral criteria and diagnostic strategies. Survival in IPAH, PAH-SSc and CTEPH was superior to that described in historical series [42-45] and age at diagnosis in IPAH has increased from 34 yrs in the National Institutes of Health (Bethesda, MD, USA) registry to $55 \pm 16$ yrs in our cohort, in keeping with other observations [12, 29, 30, 42]. Notably, the proportion of patients with $\mathrm{PAH}$ associated with HIV was lower than observed elsewhere [29, 30], which may be related to a lower prevalence of HIV in the UK [46] and differing epidemiological factors in HIV acquisition. The observed incidence of diagnosed PAH and CTEPH increased markedly during the study period, in keeping with increased awareness of these conditions. The incidences at the end of the study period are comparable to those observed in other large registries and are indicative of the success of the UK PH network [3, 29, 30, 33].

Several significant observations were made regarding patients identified at a specialist referral centre with group 2 (PH-LHD) and group 3 (PH-lung). Apart from significantly elevated right atrial pressures, patients with PH-LHD had less severe pulmonary haemodynamic abnormalities compared with IPAH, including only modest increases in PVR. This observation has recently been described elsewhere [47]; however, we were also able to define long-term survival in this patient group. In particular, in patients with PH-LHD-diastolic, survival was greatly superior to IPAH. In the PH-lung group, those patients with sleep-disordered breathing or alveolar hypoventilation had significantly higher cardiac indices and superior outcomes compared with those with parenchymal or airways disease. This emphasises the need for adequate investigation of patients with severe unexplained $\mathrm{PH}$, particularly assessment with RHC, appropriate radiology and overnight oximetry, to ensure patients with PH-LHD or PH-lung are not misdiagnosed as IPAH, resulting in inappropriate management and prognostication. An important caveat is that this cohort comprises, and thus reflects, the population of patients referred to a supra-regional pulmonary vascular unit with unexplained $\mathrm{PH}$ or in whom the elevation in $\bar{P}_{\text {pa }}$ was thought to be out of proportion to the severity of the underlying cardiac or respiratory disease. Therefore, it is not representative of all patients with PH-LHD and PH-lung. Although PH-LHD-diastolic was the most common form of PH-LHD in our registry, it is generally thought that PH-LHD-systolic is more common in the population as a whole, but is referred infrequently to a specialist centre, since a diagnosis of IPAH is less likely to be considered. Similarly, the $\mathrm{PH}$-lung patients within this registry represent a skewed sample, since in the majority of patients with $\mathrm{PH}$ associated with respiratory disease, the $\mathrm{PH}$ is mild (cor pulmonale) and is not referred for further assessment. Although the numbers of patients with PH-LHD and PH-lung were smaller than with $\mathrm{PAH}$ and CTEPH in our registry, in the population as a whole the numbers of patients with PH-LHD and PH-lung are clearly significantly higher. Importantly, however, our findings provide prognostic information to inform clinicians counselling patients with more severe PH in the context of LHD and lung disease.

A small number of previous studies have compared outcomes between selected different forms of PAH [30, 35], while national registries have either focused on a single $\mathrm{PH}$ group or PAH subtype [3, 18, 32, 33, 42]. A single study previously compared outcomes of groups 1, 3 and 4 but enrolled only 222 patients, while the methodology was unclear [48]. A recognised criticism of several previous registries is the fact that the 
majority of patients included were prevalent cases (i.e. had been diagnosed prior to enrolment) [29-31, 49-51]. It has recently been demonstrated that prevalent cases of PAH have more stable disease with superior outcomes compared with incident cases. Thus, it is possible that registries that include prevalent patients give a less reliable picture of the true natural history. It must be acknowledged, however, that although incident registries probably provide the best representation of survival for the cohort as a whole, registries based on large numbers of prevalent cases may provide extremely useful prognostic information for a previously diagnosed individual.

The main limitation of this study is its single-centre nature, but this allowed exhaustive interrogation of patient records, enabling excellent data completeness.

\section{Conclusion}

This registry describes baseline characteristics and survival for a large cohort of consecutive, treatment-naïve patients referred for evaluation of suspected $\mathrm{PH}$ at a specialist $\mathrm{PH}$ centre. Outcomes in contemporaneous patients with $\mathrm{PAH}$ and CTEPH differed depending on diagnostic subgroup and, within $\mathrm{CTEPH}$, on surgical intervention. This study also demonstrates the poor outcome in increasingly recognised subgroups of $\mathrm{PH}-$ LHD and PH-lung, which are a focus of active research. Accurate classification of pulmonary vascular disease by systematic assessment not only informs management but also provides prognostic information.

\section{SUPPORT STATEMENT}

J. Hurdman is part funded as a clinical research fellow by an unrestricted educational grant from Actelion. R. Condliffe, C.A. Elliot, J.M. Wild, A. Lawrie, I. Sabroe and D.G. Kiely are investigators within the National Institute for Health Research Sheffield Cardiovascular Biomedical Research Unit. A. Lawrie is funded by a Medical Research Council Career Development Award (G0800318).

\section{STATEMENT OF INTEREST}

Statements of interest for J. Hurdman, R. Condliffe, C.A. Elliot, C. Davies, C. Hill, J.M. Wild, D. Capener, P. Sephton, N. Hamilton, I.J. Armstrong, C. Billings, I. Sabroe, L. O'Toole and D.G. Kiely can be found at www.erj.ersjournals.com/site/misc/statements.xhtml

\section{REFERENCES}

1 Simonneau G, Robbins IM, Beghetti M, et al. Updated clinical classification of pulmonary hypertension. J Am Coll Cardiol 2009; 54: Suppl. 1, S43-S54.

2 Galie N, Palazzini M, Manes A. Pulmonary arterial hypertension: from the kingdom of the near-dead to multiple clinical trial metaanalyses. Eur Heart J 2010; 31: 2080-2086.

3 Condliffe R, Kiely DG, Gibbs JS, et al. Improved outcomes in medically and surgically treated chronic thromboembolic pulmonary hypertension. Am J Respir Crit Care Med 2008; 177: 1122-1127.

4 Archibald CJ, Auger WR, Fedullo PF, et al. Long-term outcome after pulmonary thromboendarterectomy. Am J Respir Crit Care Med 1999; 160: 523-528.

5 National Pulmonary Hypertension Centres of the UK and Ireland. Consensus statement on the management of pulmonary hypertension in clinical practice in the UK and Ireland. Thorax 2008; 63: Suppl. 2, ii1-ii41.

6 NHS National Specialised Commissioning Group. Interim Commissioning Policy. Target Therapies for the Treatment of Pulmonary Arterial Hypertension in Adults. National Health
Service, 2009. Available from www.emscg.nhs.uk/library/ P009V1NationalSpecialisedCommissioningGroupPolicy2.pdf.

7 National Audit of Pulmonary Hypertension 2010. First annual report: key findings from the National Audit of Pulmonary Hypertension for the United Kingdom, Channel Islands and Isle of Man. Report for the audit period April 2009 to March 2010. Document ref: IC05010111. Leeds, National Health Service Information Centre for Health and Social Care, 2010. Available from www.ic.nhs.uk/webfiles/NCASP/Heart\%20Disease/NHS IC_PH_Audit_INTERACTIVE_18-01-11.pdf.

8 Singh SJ, Morgan MD, Scott S, et al. Development of a shuttle walking test of disability in patients with chronic airways obstruction. Thorax 1992; 47: 1019-1024.

9 Dimopoulos K, Inuzuka R, Goletto S, et al. Improved survival among patients with Eisenmenger syndrome receiving advanced therapy for pulmonary arterial hypertension. Circulation 2010; 121: 20-25.

10 Kawut SM, Horn EM, Berekashvili KK, et al. New predictors of outcome in idiopathic pulmonary arterial hypertension. Am J Cardiol 2005; 95: 199-203.

11 Rich S, Dantzker DR, Ayres SM, et al. Primary pulmonary hypertension. A national prospective study. Ann Intern Med 1987; 107: 216-223.

12 Thenappan T, Shah SJ, Rich S, et al. Survival in pulmonary arterial hypertension: a reappraisal of the NIH risk stratification equation. Eur Respir J 2010; 35: 1079-1087.

13 Chaouat A, Naeije R, Weitzenblum E. Pulmonary hypertension in COPD. Eur Respir J 2008; 32: 1371-1385.

14 Cottin V, Le Pavec J, Prévot G, et al. Pulmonary hypertension in patients with combined pulmonary fibrosis and emphysema syndrome. Eur Respir J 2010; 35: 105-111.

15 Galiè N, Hoeper MM, Humbert M, et al. Guidelines for the diagnosis and treatment of pulmonary hypertension: the Task Force for the Diagnosis and Treatment of Pulmonary Hypertension of the European Society of Cardiology (ESC) and the European Respiratory Society (ERS) endorsed by the International Society of Heart and Lung Transplantation (ISHLT). Eur Respir J 2009; 34: 1219-1263.

16 Paulus WJ. Novel strategies in diastolic heart failure. Heart 2010; 96: $1147-1153$.

17 Zile MR, Brutsaert DL. New concepts in diastolic dysfunction and diastolic heart failure. Part I: diagnosis, prognosis, and measurements of diastolic function. Circulation 2002; 105: 1387-1393.

18 Condliffe R, Kiely DG, Peacock AJ, et al. Connective tissue diseaseassociated pulmonary arterial hypertension in the modern treatment era. Am J Respir Crit Care Med 2009; 179: 151-157.

19 Launay D, Mouthon L, Hachulla E, et al. Prevalence and characteristics of moderate to severe pulmonary hypertension in systemic sclerosis with and without interstitial lung disease. J Rheumatol 2007; 34: 1005-1011.

20 de Groote P, Gressin V, Hachulla E, et al. Evaluation of cardiac abnormalities by Doppler echocardiography in a large nationwide multicentric cohort of patients with systemic sclerosis. Ann Rheum Dis 2008; 67: 31-36.

21 Meune C, Avouac J, Wahbi K, et al. Cardiac involvement in systemic sclerosis assessed by tissue-doppler echocardiography during routine care: a controlled study of 100 consecutive patients. Arthritis Rheum 2008; 58: 1803-1809.

22 Haest I, Kiely DG, Needham L, et al. North Derbyshire, South Yorkshire and Bassetlaw Commissioning Consortium (NORCOM) Policy on Pulmonary Hypertension. Sheffield, Sheffield Public Health Network, 2004. Available from www.doncasterpct.nhs.uk/ documents / Appendix2.pdf.

23 Rich S, Kaufmann E, Levy PS. The effect of high doses of calciumchannel blockers on survival in primary pulmonary hypertension. N Engl J Med 1992; 327: 76-81. 
24 Sitbon $\mathrm{O}$, Humbert M, Jais X, et al. Long-term response to calcium channel blockers in idiopathic pulmonary arterial hypertension. Circulation 2005; 111: 3105-3111.

25 Galiè N, Hoeper MM, Humbert M, et al. Guidelines for the diagnosis and treatment of pulmonary hypertension: the Task Force for the Diagnosis and Treatment of Pulmonary Hypertension of the European Society of Cardiology (ESC) and the European Respiratory Society (ERS), endorsed by the International Society of Heart and Lung Transplantation (ISHLT). Eur Heart J 2009; 30: 2493-2537.

26 Hoeper MM, Gall H, Seyfarth HJ, et al. Long-term outcome with intravenous iloprost in pulmonary arterial hypertension. Eur Respir J 2009; 34: 132-137.

27 Vonk Noordegraaf A, Naeije R. Right ventricular function in scleroderma-related pulmonary hypertension. Rheumatology (Oxford) 2008; 47: Suppl. 5, v42-v43.

28 Overbeek MJ, Vonk MC, Boonstra A, et al. Pulmonary arterial hypertension in limited cutaneous systemic sclerosis: a distinctive vasculopathy. Eur Respir J 2009; 34: 371-379.

29 Humbert M, Sitbon O, Chaouat A, et al. Pulmonary arterial hypertension in France: results from a national registry. $A m \mathrm{~J}$ Respir Crit Care Med 2006; 173: 1023-1030.

30 Thenappan T, Shah SJ, Rich S, et al. A USA-based registry for pulmonary arterial hypertension: 1982-2006. Eur Respir J 2007; 30: 1103-1110.

31 Chung L, Liu J, Parsons L, et al. Characterization of connective tissue disease-associated pulmonary arterial hypertension from REVEAL: identifying systemic sclerosis as a unique phenotype. Chest 2010; 138: 1383-1394.

32 Badesch DB, Raskob GE, Elliott CG, et al. Pulmonary arterial hypertension: baseline characteristics from the REVEAL Registry. Chest 2010; 137: 376-387.

33 Peacock AJ, Murphy NF, McMurray JV, et al. An epidemiological study of pulmonary arterial hypertension. Eur Respir J 2007; 30: 104-109.

34 Fisher MR, Mathai SC, Champion HC, et al. Clinical differences between idiopathic and scleroderma-related pulmonary hypertension. Arthritis Rheum 2006; 54: 3043-3050.

35 Kawut SM, Taichman DB, Archer-Chicko CL, et al. Hemodynamics and survival in patients with pulmonary arterial hypertension related to systemic sclerosis. Chest 2003; 123: 344-350.

36 Tanaka E, Harigai M, Tanaka M, et al. Pulmonary hypertension in systemic lupus erythematosus: evaluation of clinical characteristics and response to immunosuppressive treatment. J Rheumatol 2002; 29: 282-287.

37 Asherson RA, Higenbottam TW, Dinh Xuan AT, et al. Pulmonary hypertension in a lupus clinic: experience with twenty-four patients. J Rheumatol 1990; 17: 1292-1298.
38 Jais X, Launay D, Yaici A, et al. Immunosuppressive therapy in lupus- and mixed connective tissue disease-associated pulmonary arterial hypertension: a retrospective analysis of twenty-three cases. Arthritis Rheum 2008; 58: 521-531.

39 Dawson JK, Goodson NG, Graham DR, et al. Raised pulmonary artery pressures measured with Doppler echocardiography in rheumatoid arthritis patients. Rheumatology (Oxford) 2000; 39: 1320-1325.

40 Bunch TW, Tancredi RG, Lie JT. Pulmonary hypertension in polymyositis. Chest 1981; 79: 105-107.

41 Launay D, Hachulla E, Hatron PY, et al. Pulmonary arterial hypertension: a rare complication of primary Sjögren syndrome: report of 9 new cases and review of the literature. Medicine (Baltimore) 2007; 86: 299-315.

42 D'Alonzo GE, Barst RJ, Ayres SM, et al. Survival in patients with primary pulmonary hypertension. Results from a national prospective registry. Ann Intern Med 1991; 115: 343-349.

43 Koh ET, Lee P, Gladman DD, et al. Pulmonary hypertension in systemic sclerosis: an analysis of 17 patients. Br J Rheumatol 1996; 35: 989-993.

44 Lewczuk J, Piszko P, Jagas J, et al. Prognostic factors in medically treated patients with chronic pulmonary embolism. Chest 2001; 119: 818-823.

45 Riedel M, Stanek V, Widimsky J, et al. Longterm follow-up of patients with pulmonary thromboembolism. Late prognosis and evolution of hemodynamic and respiratory data. Chest 1982; 81: 151-158.

46 World Health Organization Global Health Observatory Database. HIV /AIDS: Data on the size of the epidemic: Number of people (all ages) living with HIV. http://apps.who.int/ghodata/ Date last accessed: February 16, 2011.

47 Thenappan T, Shah SJ, Gomberg-Maitland M, et al. Clinical characteristics of pulmonary hypertension in patients with heart failure and preserved ejection fraction. Circ Heart Fail 2011; 4: 257-265.

48 Fischler M, Speich R, Dorschner L, et al. Pulmonary hypertension in Switzerland: treatment and clinical course. Swiss Med Wkly 2008; 138: 371-378.

49 Benza RL, Miller DP, Gomberg-Maitland M, et al. Predicting survival in pulmonary arterial hypertension: insights from the Registry to Evaluate Early and Long-Term Pulmonary Arterial Hypertension Disease Management (REVEAL). Circulation 2010; 122: $164-172$.

50 Humbert M, Sitbon O, Chaouat A, et al. Survival in patients with idiopathic, familial, and anorexigen-associated pulmonary arterial hypertension in the modern management era. Circulation 2010; 122: $156-163$.

51 Humbert M, Sitbon O, Yaïci A, et al. Survival in incident and prevalent cohorts of patients with pulmonary arterial hypertension. Eur Respir J 2010; 36: 549-555. 